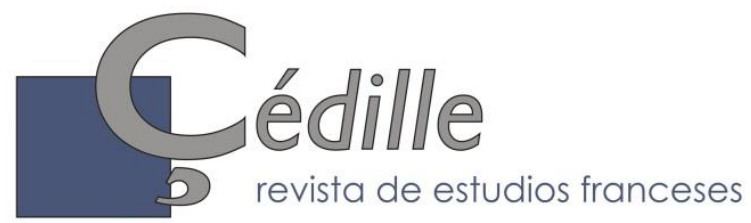

ISSN: 1699-4949

$n^{0} 18$ (otoño de 2020)

Monografías 11

Epistemocrítica: análisis literario y saber científico

Amelia Gamoneda Lanza \& Francisco González Fernández, editores científicos

\title{
La domesticación del infinito: las matemáticas en Lautréamont, entre lo discreto y lo continuo
}

\author{
Mauricio Cheguhem RIANI \\ Universidad de Salamanca \\ mauriche8@gmai.com \\ ORCID: 0000-0003-3286-0278
}

\section{Resumen}

La literatura de Isidore Ducasse está atravesada por los saberes que han monopolizado el conocimiento científico del siglo XIX. Sin embargo, probablemente sea la matemática la que se erige como una fuente inagotable de conocimiento a partir de su búsqueda o domesticación del infinito. Ahora bien, esto no pretende anular o abrogar este problema matemático de envergadura filosófica, sino subrayar el rol activo de la literatura para aprehender, interrogar y proyectar el conocimiento científico sobre el entramado cultural y epistemológico. Por este motivo, el presente artículo pretende analizar la influencia de la matemática en Ducasse, la metáfora del mar como signo del infinito y la mirada poética que discurre entre lo discreto y lo continuo bajo el signo de Proteo.

Palabras clave: Isidore Ducasse, Filosofía de la matemática, Infinito, Literatura y Ciencia, Poesía y Matemática.

\section{Résumé}

La littérature d'Isidore Ducasse est traversée par les savoirs qui ont monopolisé la connaissance scientifique du XIX ${ }^{\mathrm{e}}$ siècle. Pourtant, les mathématiques s'érigent sans doute comme une source inépuisable de connaissance à partir d'une recherche ou d'une domestication de l'infini. Or, ici la question n'est pas d'annuler ou de révoquer ce problème mathématique d'envergure philosophique, mais de souligner le rôle actif de la littérature au moment d'appréhender, d'interroger et de projeter la connaissance scientifique sur le réseau culturel et épistémologique. Pour cette raison, cet article a l'intention d'analyser l'influence de la mathématique sur sa littérature, la métaphore de la mer comme signe de l'infini et le regard poétique qui glisse entre le discret et le continu sous la trace de Protée.

Mots clé : Isidore Ducasse, Philosophie des mathématiques, L’infini, Littérature et Science, Poésie et maths.

\section{Abstract}

\footnotetext{
*Artículo recibido el 25/02/2020, aceptado el 27/10/2020.
} 
The literature of Isidore Ducasse is crossed by the knowledge that has monopolized the scientific thought of the nineteenth century. However, mathematics stands as an inexhaustible source of knowledge from its quest or domestication of infinity. However, the domestication of infinity indicated does not mean to annul or repeal this mathematical problem of philosophical importance, but to raise awareness of the active role of literature for apprehending, questioning and projecting scientific knowledge over the cultural and epistemological framework. Ducasse's writing makes of this epistemological problem the gordian knot where mathematics, metaphysics and poetry intersect. For this reason, the present article aims to analyze the influence of mathematics in its literature, the metaphor of the sea as a sign of infinity, the poetic view that runs between the discrete and the continuous and the transfinite and infinitesimal mathematics under the sign of Proteo, God of logos and number.

Keywords: Isidore Ducasse, Math philosophy, Infinite, Literature and science, Poetry and math.

\section{Introducción: breve historia del infinito}

Resulta necesario señalar que la ansiedad que despierta el concepto de infinito es transversal al conocimiento humano: matemática, filosofía y literatura han domesticado nuestra conciencia a la hora de abarcar lo ilimitado. En el principio, etapa auroral de Grecia, el infinito se había cifrado bajo la forma del vacío, to apeiron: «sustrato ilimitado del que provino el mundo», como afirma Anaximandro ${ }^{1}$.

El carácter metafísico del pensamiento presocrático advertía sobre la posibilidad de un territorio desprovisto de toda materia, algo así como un tiempo de formas puras. La visión genésica de Anaximandro instala la idea de un tiempo anterior a la forma, algo así como un gran vacío. Por tanto, cabe observar que el concepto de infinito está sujeto aquí a dos dimensiones, tal y como apunta Puig (2009: 134): una temporal (inmortal, eterna, sin final) y otra espacial (inconmensurable, informe, interminable). Pero en ambos casos la dificultad se encuentra en el ejercicio de abstracción de dicho concepto y su aplicación real en el mundo ${ }^{2}$.

En este sentido no son de extrañar los intentos más o menos exitosos de domesticación. ¿A qué nos referimos exactamente? A los lenguajes que han fraguado su sentido y ocupan un papel protagónico en esta empresa. Ya para Platón, «fundamentalmente en el Timeo, hay tres figuraciones principales de lo

\footnotetext{
${ }^{1}$ Este artículo ha sido realizado en el marco de las actividades del Proyecto de I+D de Excelencia Inscripciones literarias de la ciencia: cognición, epistemología y epistemocrítica (ILICIA) del Ministerio de Economía y Competitividad. Ref. FF12017-83932-P.

${ }^{2}$ Al respecto: «[la palabra apeiron] cabe traducirla por "la ausencia de límite" si y sólo si somos capaces de no olvidar ni por un momento que en griego "límite" es "ser" y "ausencia de límite" es "no ser"; límite es figura, configuración, por lo tanto ser algo. Que la arkhé es la ausencia de límite quiere decir que su condición de arkhé consiste en su escaparse, en su sustraerse; escapándose ello mismo, deja ser cada cosa, deja que cada cosa tenga lugar» (Martínez Marzoa, 1995: 22).
} 
ilimitado: la matemática, la música y el misticismo» (Steiner, 2005: 63-64). Primordialmente, los platónicos, «gendarmes espirituales de Apolo», señalaban la matemática como el lenguaje más abstracto y por tanto universal del pensamiento. $\mathrm{Su}$ arquitectura auguraba un tiempo de las formas puras o ideales porque «su significado es siempre perfectamente íntegro y accesible "directamente" a la razón: entender un enunciado matemático es descubrir de algún modo una verdad concebida divinamente» (Tasic, 2001: 10).

Sin embargo, tanto para Platón como para la Divina Hermandad de Pitágoras, el apeiron indicaba esencialmente un espacio que, más allá de ser ilimitado, era fundamentalmente caótico. Lo que comenzó siendo una explicación del origen se convierte en un rompecabezas para el razonamiento matemático. En efecto, el infinito que pasa de los presocráticos al esplendor de Grecia adquiere características negativas: se convierte en fuente de confusión y obstáculo para el despliegue del pensamiento racional $^{3}$.

Antes que nada, cabe advertir que, desde el punto de vista de la matemática helénica, el infinito se refiere esencialmente a dos dimensiones. Por un lado, lo infinitamente grande y por otro lo infinitamente pequeño. Podemos subrayar en este razonamiento una corriente transfinita y otra infinitesimal de las matemáticas. En el mismo sentido, Aristóteles escribió que se entiende por «infinito» aquello que es o bien respecto a su tamaño, o bien respecto a su divisibilidad ${ }^{4}$.

Lo que anuncia en la Física (VI, 2, 233a) es una de las primeras intuiciones de la matemática. En efecto, frente a una línea podemos trazar dos clases de infinitos. El primero de ellos se encuentra en el recorrido ilimitado de números naturales, mientras que el otro se encuentra en la división infinita entre dos puntos de un recorrido. En el mundo griego, el mito de «Aquiles y la tortuga» anunciaba lo que hoy conocemos por números fraccionarios. La paradoja de Zenón de Elea atiende específicamente al recorrido infinito entre dos puntos, lo que en matemática se traduce del siguiente modo: $10+1+1 / 10+1 / 100+1 / 1000$ $+1 / 1000 \ldots$ Señalamos aquí un pequeño infinito, pero tan ilimitado como el primero. ${ }^{5}$

Frente a la complejidad epistemológica, la doctrina aristotélica apostó por zanjar este problema de la física asegurando que el infinito no es en definitiva un ente real, sino más bien una potencia. En todo caso, para Aristóteles no existe tal cosa como un espacio infinito, sino que el espacio -en tanto tal- es

\footnotetext{
${ }^{3}$ «Para Platón y Pitágoras el infinito era apeiron, el caos, el infinito carecía de medida: metron. La voz "apeiron" tal como la emplea Anaximandro, significa "sin fin" o "sin límite", suele traducirse como "lo infinito", "lo indefinido", "lo ilimitado"» (Ortiz, 1994: 61).

4 «Porque tanto la longitud como el tiempo, y en general todo continuo, se dice que son infinitos de dos maneras: o por división o por sus extremos» (Aristóteles, 1995: 344-345).

5 «Si el Gran $\infty$, el infinito en extensión, está a la derecha interminable de la recta numérica, el Pequeño $\infty$ que Zenón explota se halla en el intervalo de aspecto totalmente finito entre 0 y 1 . Zenón revela que dicho intervalo contiene un número infinito de puntos intermedios...» (Foster Wallace, 2013: 78).
} 
potencialmente infinito. Las palabras del Estagirita escenifican un fin de las especulaciones sobre dicho concepto. En palabras del escritor y matemático David Foster Wallace (2013: 90): «La doctrina aristotélica se convirtió en dogma de la Iglesia, y parte de la doctrina aristotélica era la consideración del infinito como solo potencial, una ficción abstracta y origen de confusión, to apeiron, territorio reservado a Dios, etc.».

En conclusión, el peso metafísico se desploma sobre los canales de la matemática. Origen de confusión, el infinito pasa a ocupar un papel marginal dentro de las investigaciones del matema porque se priorizó su carácter metafísico. Por ello, un halo de misticismo se posó sobre esta figura a la espera de la modernidad y el desarrollo del cálculo.

En efecto, habrá que esperar al siglo XVII para un cambio drástico en lo referente a este asunto. El símbolo del infinito $(\infty)$ fue introducido por John Wallis en su obra de 1655, Arithmetica Infinitorum, con el nombre técnico de lemniscata, cuyo origen griego significa «cinta». La analogía apunta a la ausencia de principio o final y sugiere al mismo tiempo un nexo entre las dos dimensiones: una espacial y otra temporal. Pero habrá que aguardar al ocaso del XVII para una ruptura definitiva con la tradición aristotélica, dado que Galileo y Nicolás de Cusa retoman el concepto de espacios infinitos. Este salto de la ciencia sobre la parálisis metafísica abre un debate amplio sobre las posibilidades de su ejecución práctica y más precisamente sobre el papel de las matemáticas en esta empresa. En efecto, Galileo se «convierte [...] en el hombre que descubrió las lunas de Júpiter, reordenó el cosmos [...] y realizó la famosa proclama de que el "gran libro" de la naturaleza está escrito en el lenguaje de las matemáticas» (Jay Gould, 2004: 15-16).

Sin embargo, es en el caso excepcional de Leibniz donde el apeiron adquiere otra función, puesto que, como indica Paolo Zellini, el autor de la Teodicea es el responsable de «traducir el óx 89). Se ejerce entonces, en los albores del siglo XVIII, un final del concepto negativo de infinito: lo caótico, lo confuso o lo incognoscible. En consecuencia, la incorporación de este elemento en el enunciado matemático revoluciona la filosofía de la ciencia y su praxis a partir del cálculo, la función continua y las series infinitas.

No es de extrañar que, en plena dominación del infinito, la matemática se convierta -en la estela platónica- en la última esperanza de la metafísica. Pero más allá de este aspecto, debemos resaltar su aplicación en las ciencias del compor-tamiento. De modo culminante en el siglo XIX, el positivismo había desplegado la fórmula matemática sobre los demás campos del saber. La Filosofía de la matemática o la Aritmética de la vida humana (Béguin, 1967: 70) comenzaban a relacionar los patrones que unificaban las estaciones, los astros, las plantas y las bestias; en definitiva: se apoderaba de la naturaleza.

El desarrollo acelerado del cálculo permitió una expansión del pensamiento científico y puso en vértigo toda la cadena productiva, tecnológica e 
industrial del siglo XIX. La visión de la máquina como resultado del proceso científico permitió una mirada crítica por parte de algunos artistas e intelectuales sobre la mecánica, la matemática e incluso la óptica. Por ejemplo, Blake y Keats acusaban a Isaac Newton porque éste había «despoetizado el mundo del hombre y lo había despojado de su significado» (Huxley, 1964: 131). La postura reaccionaria de los poetas insulares ilumina la resistencia por parte de la literatura a aceptar el lugar que la matemática estaba ocupando en el discurso científico y humano.

En conclusión, resulta indudable el papel que el infinito, instalado primordialmente por Leibniz, ha tenido en el desarrollo del cálculo. Son las figuras de Cantor, Dedekind y Weiestrass las que ejercen de vanguardia para un nuevo período del infinito como ente matemático. Fundamentalmente en Cantor, el ejercicio radica en unificar los números racionales e irracionales bajo un mismo conjunto $^{6}$. Para ello, el matemático rompe con la visión dualista (transfinito/infinitesimal) y crea la posibilidad de «toda una torre de infinitos, una jerarquía interminable de diferentes clases de infinito» (Martínez, 2007: 49).

\section{Las matemáticas en Les Chants de Maldoror: una aproximación epistemocrítica}

La escritura de Isidore Ducasse (cuyo seudónimo en esta obra era Lautréamont) -figura misteriosa y esquiva incluso para sus propios biógrafos- no es ajena al paradigma científico de su tiempo, sino que se enmarca en la búsqueda del infinito a partir de distintas ramas del saber, pero particularmente el matemático. En efecto, la escritura del franco-uruguayo se condensa en Les Chants como un collage que reúne la narrativa gótica, las disquisiciones entre el bien y el mal, fragmentos enteros de la enciclopedia natural y conceptos de matemática y metafísica ( $c f$. Fernández Urtasun, 1999).

El concierto de saberes que se despliegan en el aparato de su literatura nos advierte sobre la íntima relación que tiene el poeta con el conocimiento científico de su tiempo. Ducasse demuestra, más allá de su mirada cruel sobre la humanidad, un interés permanente por el conocimiento científico y particularmente el matemático. En el ya clásico ensayo Lautréamont, Gastón Bachelard (1939: 59) apunta en el mismo sentido: «Ce que la biographie ne dit pas, l'œuvre le chante. Il y a quelques pages dans les Chants de Maldoror qui se calment et s'élèvent ; ces pages sont un hymne aux mathématiques». En este sentido, el propio narrador confiesa: «Il se mit à sourire en recevant les coups, et leur parla avec tant de sentiment, d'intelligence sur beaucoup de sciences humaines qu'il avait étudiées [...]» (Ducasse, 1988: 162).

La rareza o malditismo que muchos de sus críticos han subrayado no dinamita la capacidad de asombro del poeta a la hora de destacar a la ciencia

\footnotetext{
${ }^{6}$ En esta misma línea: «Oponiéndose a la imagen tradicional del infinito como un único, inimaginable e inmenso número, George Cantor, a finales del siglo XIX, introdujo los conjuntos infinitos en la matemática como entes matemáticos perfectamente legítimos» (Jofre, 1999: 148).
} 
como una experiencia heurística. Por ello, es necesario asumir una perspectiva epistemocrítica, tal como lo entiende Michel Pierssens: ¿cuáles son los saberes que orbitan en su obra? ¿Cuáles las relaciones que tienen entre sí y de qué manera influye la matemática en su pensamiento literario ${ }^{7}$ ?

En este sentido, resulta necesario señalar el impacto de los nuevos descubrimientos e invenciones de su tiempo. Como habíamos apuntado, el espíritu del siglo XIX estuvo signado por la física de Newton y el desarrollo de la maquinaria pesada que dio lugar a la revolución industrial, científica y tecnológica $^{8}$. Lautréamont no es ajeno a su época e instrumentaliza en su beneficio conceptos que provienen de la óptica, la ingeniería mecánica o la biología, entre otros. El conocimiento enciclopedista que se refleja en Les Chants no colisiona con el espíritu decadente y escéptico que rige su escritura, sino que la ciencia se vuelve una herramienta para destronar al propio demiurgo y su representante en la tierra: el hombre.

Probablemente sea la matemática quien mejor represente este gesto destructivo del poeta, puesto que se convierte en un lenguaje superior al propio Dios. De esta manera, Lautréamont esgrime una filosofía de la matemática que nuclea la ética, la metafísica y la lógica. No es de extrañar, en este sentido, la relación que comienza a asumir con el resto de los saberes: «Sans vous [mathématiques], dans ma lutte contre l'homme, j'aurais peut-être été vaincu» (Ducasse, 1988: 192).

Ahora bien, cabe señalar que la relación entre poesía y matemática ha tenido al menos dos caminos distintos en el correr del siglo XIX. El primero de ellos, como hemos señalado, encuentra en Blake y Keats los representantes de la resistencia literaria contra el avance del cálculo. La renuencia de estos poetas atiende al modelo totalizante y domesticador de la matemática sobre la naturaleza. Pero cabe señalar la otra vía que atraviesa el pensamiento decimonónico y abre la posibilidad de un entendimiento mayor entre ambos lenguajes.

Probablemente sea Novalis el mejor representante de esta corriente que intenta alejar los aspectos más crudos y calculadores de la matemática para ungirla, al igual que la poesía, con el misterio de la creación. En efecto, el alemán poetiza la matemática y matematiza la poesía: «Lo maravilloso de las Matemáticas. Son instrumento de escritura, susceptible aún de un perfeccionamiento infinito; son una prueba esencial de la simpatía y de la identidad que existen entre la Naturaleza y nosotros» (Novalis, 1944: 184).

\footnotetext{
${ }^{7}$ Michel Pierssens (1990: 14) escribe: «La question à chaque fois sera posée : que sait un texte ? Mais aussi : comment le texte fait-il de son propre déploiement la réponse à cette question sur quoi il joue son existence et son sens, en visant à nouer de nouveaux noeuds dans la langue, les figures, les discours, les sujets?».

${ }^{8}$ Para esto ver: «Descubrimientos [del siglo XIX] como la radioactividad, la relatividad, el átomo, la cuarta dimensión, el automatismo psicológico, la interpretación científica de los sueños, los avances ópticos, la cada vez más cercana posibilidad de volar y de hacer realidad los sueños de Leonardo abren una nueva conciencia de los tiempos modernos» (Parcerisas, 2006: 151).
} 
El matrimonio entre poesía y matemática parece ahora posible en la medida en que ambas pretenden la estructura íntima de la naturaleza y cuyo origen se encuentra en el mundo de las formas puras, tal como lo habían concebido los platónicos. En este sentido, la poesía se hermana con la matemática a la hora de crear un proyecto común: algo así como el lenguaje de un absoluto ${ }^{9}$. En el mismo sentido se expresa Isidore Ducasse (1988: 186) en el canto segundo de Les Chants de Maldoror:

O mathématiques sévères, je ne vous ai pas oubliées. Depuis que vos savantes leçons, plus douces que la miel, filtrèrent dans mon cœur, comme une onde rafraîchissante. J'aspirais instinctivement, dès le berceau, à boire à votre source, plus ancienne que le soleil, et je continue encore de fouler le parvis sacré de votre temple solennel, moi, le plus fidèle de vos initiés.

El neoplatonismo que sobrevuela la obra de Lautréamont pretende situar a la matemática bajo la luz de las fuerzas divinas, como una suerte de inscripción teleológica que mueve el sol y las demás estrellas. La imagen solar de la matemática, en clara alusión a Apolo, nos invita a reflexionar sobre el sistema de iluminación de esta literatura. En efecto, el heliotropismo matemático se desborda y configura el orden del mundo. Por ello, es posible inscribir a Lautréamont en la vía de reconciliación entre ambas esferas del conocimiento, pero apuntalando su naturaleza metafísica.

De este modo, el poeta no duda en situarse dentro de los pitagóricos a la hora de señalar a la matemática como una suerte de ontología. La estetización de la matemática, similar al caso de Novalis, se asemeja a la santísima trinidad platónica de la Idea, pero en este caso: «Arithmétique ! algèbre ! géométrie ! trinité grandiose ! triangle lumineux !» (Ducasse, 1988: 188).

De esta manera, Lautréamont (1988: 188) concibe la matemática en el origen de la creación, un tiempo anterior al sol: «enchaînement rigoureux de vos propositions tenaces et la constance de vos lois de fer, vous faites luire, aux yeux éblouis, un reflet puissant de cette vérité suprême dont on remarque l'empreinte dans l'ordre de l'univers». Si bien hemos señalado que la visión metafísica de los pitagóricos reconoce la realidad ontológica de la matemática, será el neoplatonismo

-principalmente a partir de Plotino- quien promueva la creencia de un encadenamiento desde el más «sagrado templo» de la Idea hasta el mundo de la materia ${ }^{10}$.

\footnotetext{
${ }^{9} \mathrm{Al}$ respecto, cabe señalar que «en las matemáticas no veía Novalis un simple almacén de símiles con los que traducir sus ideas sobre la poesía, sino una vía real para alcanzar lo absoluto» (González Fernández, 2012: 72).

${ }^{10}$ En este sentido, cabe señalar que «Muchos siglos después sería Plotino quien lo enunciaría de un modo mucho más claro al postular que todo procede de una unidad y todo, por una necesidad natural, retorna a ella, incluso las cosas diversas y hasta contrarias» (Zellini, 2018: 136-137).
} 
Ya sea por el encadenamiento de ecuaciones y fórmulas, o por la naturaleza ontológica de sus propuestas, la matemática representa en Lautréamont una seguridad inquebrantable que supera cualquier creación del hombre. En efecto, las matemáticas «qui n'étaient que la révélation éclatante d'axiomes et d'hiéroglyphes éternels, qui ont existé avant l'univers et qui se maintiendront après lui» (Ducasse, 1988: 188) o «[mathématiques] Vos pyramides modestes dureront davantage que les pyramides d'Egypte» (Ducasse, 1988: 192).

Cabe señalar que su pensamiento viene en la estela del siglo XVIII y es en este sentido en el que aparece la figura de Descartes en su obra ${ }^{11}$. El cartesianismo había puesto a la matemática en el centro del conocimiento primario y abstracto. De esta manera, la matemática euclidiana y la epistemología de Descartes establecen las férreas cadenas del conocimiento matemático. En el mismo sentido se expresa Hersch (2010: 123): «Para Descartes, el modelo ideal que el pensamiento debe intentar alcanzar es el modelo matemático».

Sin embargo, los románticos no creían que la matemática pudiera crear una verdad que enjaule el ser bajo una fórmula, sino que la verdad se revela en el interior del sujeto, ya sea matemático o poético. Por tanto, lo que se radicaliza es el idealismo en sus formas más puras: la verdad se encuentra adentro del sujeto. Como afirma González Fernández (2012: 70): «Para los románticos el auténtico conocimiento solo surgía cuando el hombre era poseído por la verdad».

Esta imagen súbita de la conciencia anuda particularmente la matemática con la poesía. Porque en el fondo lo que están diciendo es que la verdad es inmanente: está dentro del propio lenguaje, pero se revela como un descubrimiento heurístico de la conciencia. Por tanto, los románticos no creían en la verdad calculadora o racional de la matemática sino en el aspecto absoluto de su lenguaje universal, en el mismo sentido que la poesía:

Je voudrais que la majesté humaine ne fût que l'incarnation du reflet de la tienne. Je demande beaucoup, et ce souhait sincère est glorieux pour toi. Ta grandeur morale, image de l'infini, est immense comme la reflexión du philosophe, comme l'amour de la femme, comme la beauté divine de l'oiseau, comme les méditations du poète. Tu es plus beau que la nuit (Ducasse, 1988: 80).

Resulta evidente que Isidore Ducasse le confiere una calidad moral a la matemática. La ética que propone confronta dicha ciencia con el propio Dios. Puesto que la matemática sería para el hombre un maestro superior al propio demiurgo y de cuyos teoremas debería desplegarse la ética humana. La grandeza moral, que por otra parte está sostenida por el infinito, se asemeja a la metafísica, el amor, la estética e incluso a las meditaciones del poeta. Ducasse identifica en la matemática una propiedad humana, susceptible de ser comparada con la filosofía

\footnotetext{
${ }^{11} \mathrm{Al}$ respecto: «Le penseur Descartes faisait, une fois, cette réflexion que rien de solide n'avait été bâti sur vous. C'etait une manière ingénieuse de faire comprendre que le premier venun ne pouvait pas sur le coup découvrir votre valeur inestimable» (Ducasse, 1988: 194).
} 
y la poesía. Este texto aproxima el poeta al pensamiento de Novalis, en tanto matematiza la poesía y poetiza la matemática. Ambas pertenecen a un orden superior que bien podría superar al propio demiurgo.

De manera conclusiva, la matemática cobra relevancia no por calcular la naturaleza, sino por someter el infinito que proviene de un centro gravitatorio común, algo así como un absoluto. Para el poeta, por tanto, no se trata del cálculo de la materia, sino que resulta - como sostiene Meillassoux (2006: 48)- que lo relevante es «la capacité des mathématiques à discourir du Grand Dehors». Este espacio ilimitado adquiere en su poética la forma del agua y particularmente el del infinito.

\section{La forma del agua, reflejo del infinito}

Como hemos expresado, el infinito cifra para Lautréamont ese «Gran Afuera» que posee carácter metafísico. Por tanto, la matemática le permite al poeta hacerse con una herramienta fundamental para su sometimiento. Esta búsqueda se convierte en obsesión para el narrador de Les Chants y le permite aproximarse a la idea de humanidad que tanto desprecia. Según el francouruguayo el infinito es primordialmente un enigma de la conciencia que pronto se convertirá en obsesión: «Moi, comme les chiens, j’éprouve le besoin de l'infini...» (Ducasse, 1988: 64).

En este sentido, Ducasse encuentra en el origen de la matemática lo mismo que tan desesperadamente busca el poeta. La relevancia de la matemática en el conjunto de saberes responde a dicha aproximación metafísica, señalando su naturaleza abstracta, que le confiere un origen primogénito, anterior a toda forma: «car, le Tout-Puissant s'est révélé complément, lui et ses attributs, dans ce travail mémorable qui consista à faire sortir, des entrailles du chaos, vos trésors de théorèmes et vos magnifiques splendeurs» (Ducasse, 1988: 188).

Ese origen (arché) matemático se asemeja a la noción de infinito propuesta por Anaximandro. La gramática de la creación del presocrático apunta al infinito como caos ilimitado: to apeiron. En este sentido, el poeta retoma la tradición clásica y codifica el aspecto negativo del infinito, pero para darle una nueva vuelta de tuerca. De este modo, lo caótico se convierte en pulsión creadora de las funciones y axiomas matemáticos.

En efecto, la génesis de la matemática no implica una visión negativa del infinito. Contrario al aristotelismo, el infinito no es sencillamente un obstáculo para el pensamiento racional, sino que representa una pulsión vital para su despliegue. Finalmente, Lautréamont no posa sus ojos como los antiguos en el origen de la creación, sino que hacen relucir un «Vieil océan, aux vagues de cristal» (Ducasse, 1988: 70).

La forma del agua, en su extensión ilimitada, le permite al poeta reflexionar sobre la naturaleza del infinito a partir de la matemática, la física y la poesía. Los saberes gravitan en torno a dicho concepto que se materializa en las profundidades marinas. En el sentido indicado por los románticos, el océano representa aquello que Lacoue-Labarthe y Nancy (1978: 21) han llamado 
«absoluto»; en efecto, «Le romantisme, c'est l'inauguration de l'absolu littéraire».

De esta manera, el océano es la metáfora elegida por el poeta para inscribir el infinito desde tres saberes diferentes: matemática, física y estética. Pero será el último quien resulte determinante a la hora de identificar dicha metáfora en la estela del pensamiento romántico. Puesto que la materialidad del agua compone un paisaje de lo ilimitado, determinante para la sensibilidad del poeta. En efecto, el infinito exige una mirada que sigue «toutes voiles tendues, vers un point déterminé de l'horizon» (Ducasse, 1988: 42).

En este sentido, el problema del océano no es solamente de orden matemático o físico, sino que exige una aproximación sobre la composición del paisaje. El océano, por tanto, nos permite reflexionar sobre dos aspectos fundamentales de la percepción: en primer lugar, la naturaleza ilimitada del objeto; y en segundo lugar, la dimensión hermenéutica de dicha mirada. Pues como indica Paolo Zellini (2018: 337): «el mar suscita el sentido de lo sublime».

En efecto, el desborde de la percepción, como resultado de un horizonte infinito, aproxima este pasaje de Les Chants con las estéticas de lo sublime. Dichos paisajes, que fueron motivo de reflexión desde el empirismo inglés hasta el idealismo poskantiano, ocupan un lugar privilegiado en el presente texto. Y en modo similar al pensamiento de Kant, la estética de lo sublime avanza aquí desde una disposición romántica o subjetiva hacia una lógica de la percepción como podemos observar en Crítica del juicio.

El concepto antiguo, acuñado por Longino, describe dos estadios del conocimiento: el objetivo (cualidades primarias) y el subjetivo (cualidades secundarias). En el primer caso, el filósofo de Könisberg enlaza el espacio ilimitado con un principio matemático. Lo sublime matemático es, en efecto, lo inconmensurable de la forma: a este principio Kant lo llama de magnitud ${ }^{12}$. El horizonte ilimitado, de magnitudes desbordantes, produce en el sujeto una sensación de vértigo en la medida en que lo sublime matemático es «l'informe, l'absence de forme» (Lyotard, 2005: 26).

En consecuencia, el viejo océano de Les Chants no permite un cálculo exacto de su forma. Es en el horizonte, donde se disuelve el agua, el cielo y la mirada, donde se proyecta lo sublime matemático, tal como lo ha entendido Kant: un problema de magnitudes. Pero cabe señalar que el sentimiento de lo sublime responde a dos entidades de la conciencia: los conocimientos racional y subjetivo. La percepción de un paisaje ilimitado, por un lado, y la incapacidad por comprenderlo por el otro, condicionan las cualidades primarias y secundarias hacia una respuesta epistemológica: el océano (infinito) es incognoscible. Al igual

${ }^{12}$ Cabe desarrollar este concepto a partir de las palabras de Hernández León (2016: 42) en SerPaisaje: «Lo que Kant denomina aquí como matemáticamente sublime reside en una consideración de lo "grandioso", como atributo de "la cosa a pensar". Pero esa capacidad empírica de representación puede ser entendida tanto respecto a lo matemático como a lo dinámico; es decir, como ampliación de la intuición en el añadido de la razón». 
que la mirada, la erudición científica no ha conseguido todavía medir la «profondeur vertigineuse de tes abîmes» (Ducasse, 1988: 74):

Vieil océan, ta grandeur matérielle ne peut se comparer qu'à la mesure qu'on se fait de ce qu'il a fallu de puissance active pour engendrer la totalité de ta masse. On ne peut pas t'embrasser d'un coup d'œil. Pour te contempler, il faut que la vue tourne son télescope, par un mouvement continu, vers les quatre points de l'horizon, de même qu'un mathématicien, afin de résoudre une équation algébrique, est obligé d'examiner séparément les divers cas posibles, avant de trancher la difficulté (Ducasse, 1988: 72-74).

Ahora bien, el método de domesticación que propone Lautréamont en el canto primero es de orden científico. La mirada no es suficiente para abarcar el infinito y por tanto el poeta sugiere una aproximaxión analítica, donde lo complejo es divisible entre partes, como en el ejemplo matemático. Pero los resultados se muestran ambiguos; mientras que al principio el océano se describe como una esfera perfecta que «réjouit la face grave de la géométrie», inmediatamente señala sus irregularidades e imperfecciones: «tu es un immense bleu, appliqué sur le corps de la terre» (Ducasse, 1988: 70).

Como podemos observar, estas descripciones antitéticas del océano advierten una tensión que supera la propia forma del agua y se introduce en las crisis de los enunciados matemáticos. Como indica Philippe Sollers (1988: 163), «L'océan, les mathématiques, le tourbillon: tels sont les noms dans lesquels le texte infini accepte de se reconnaître». ¿Pero a qué se refiere con el torbellino? La escritura de Ducasse sugiere una crisis de las matemáticas a partir del concepto de infinito. ¿Pero en qué sentido? Es la consecuencia a «mille secrets de ton intime organisation» (Ducasse, 1988: 72).

Lo que se evidencia en el pensamiento del franco-uruguayo es el resquebrajamiento de los postulados ideales de la geometría clásica. En definitiva, lo que despunta es una crisis del quinto principio de Euclides que funciona como torbellino sobre el campo de las matemáticas. El paisaje sublime no significa solamente un desborde del telos o la mirada, sino que es fundamentalmente sobre la comprensión y en última instancia sobre la propia ciencia. Entre el «cuadrado perfecto» y el torbellino océanico navega el pensamiento de Lautréamont. Este amigo de Pitágoras, parece inscribir un seismo que partirá por siempre la corona metafísica de las matemáticas. En sentido similar se expresa González Fernández (2012: 193): «Antes de perecer definitivamente tenía pues el deber de escribir sobre su cadalso un último mensaje, inscribir en el cubo del zócalo la desesperación del orden sagrado y anunciar el fin del universo pitagórico, armónico y simétrico».

\section{Entre lo continuo y lo discreto bajo el signo de Proteo}

Ahora bien, la metáfora del océano no solo representa el infinito matemático entendido como apeiron, sino que también refleja la crisis de los 
fundamentos matemáticos y particularmente la del continuo. De esta manera, la forma del agua permite reflexionar sobre los dos modelos del infinito. Como podemos observar desde la Física de Aristóteles, el infinito corresponde a dos movimientos: o bien respecto a sus extremidades o bien respecto a su divisibilidad.

En efecto, el paisaje indicado por Lautréamont presenta una extensión ilimitada pero también una división imposible. En este sentido, la mirada del poeta zarpa entre lo discreto y lo continuo. ¿Pero a qué nos referimos exactamente? A la dificultad de la percepción por determinar en lo continuo un elemento de lo discreto. En otras palabras: el problema central del océano es que no permite la divisibilidad de sus partes, sino que el propio mar es en sí mismo indivisible. Como habíamos expresado anteriormente, la metáfora de Lautréamont traza dos direcciones: el continuo transfinito y lo discreto infinitesimal. En ambos casos, el océano resulta imposible de calcular, ya sea por su extensión o por su composición.

En palabras de Paolo Zellini (2018: 24), «se diría que el número 1 tiene una función intermediaria, la función de umbral crítico que separa lo infinito indiferenciado de lo finito, lo continuo de lo discreto, lo irracional de lo racional (ratio o logos), las tinieblas de la luz». En definitiva, lo 1 se convierte en la unidad mínima de aprehensión de la materia, aquello que irrumpe en el continuo infinito para dar forma a lo divisible. En conclusión, mientras que no se distinga lo 1 lo que resulta imposible es la cuenta matemática. Allí reina sobre todas las cosas el apeiron, como en el ejemplo ducassiano del océano absoluto.

El poeta sugiere los esfuerzos de la ciencia -a partir del método analíticopor determinar los límites del espacio. Empero, dicho modelo falla en determinar lo 1 y Ducasse le confiere esa aptitud a «le compas serein du philosophe» (Ducasse, 1988: 108). En definitiva, la imposibilidad de lo 1, como consecuencia de la disputa entre lo discreto y lo continuo, aparta el modelo científico para abrir el camino a la filosofía. Como expresa el poeta: «Que chacun reste dans sa nature» (Ducasse, 1988: 164).

¿Qué implica, por tanto, este problema matemático? Que el cálculo del transfinito como del infinitesimal problematizan lo 1, puesto que no existe dentro de lo continuo una forma de lo discreto. La forma del agua, en este sentido, se presenta indivisible para los ojos del poeta y refleja el problema del infinito matemático. En efecto, ¿acaso es posible contar sin determinar la mínima unidad de sentido? El océano desborda la cuenta ya sea por su división o por sus extremidades.

Una vez más, Lautréamont parece adelantarse a la crisis de los fundamentos matemáticos. En este caso, si bien la crisis del continuo tiene una primera aparición en el mito de Aquiles y la tortuga, se radicaliza durante el siglo $\mathrm{XX}$ : «Si está usted interesado, la visión personal del propio Gödel era que la hipótesis del continuo es falsa, que en realidad hay toda una infinidad de $\infty$ al estilo de Zenón»(Foster Wallace, 2013: 274-275). En definitiva, la crisis del 
continuo, desde Cantor en adelante, se da en el seno de las matemáticas transfinitas ${ }^{13}$.

Aún más, la imposibilidad de determinar lo discreto (en tanto 1) sobre el plano infinito, no solo determina la metáfora del océano, sino que sugiere una metamorfosis constante de toda la naturaleza. Por este motivo, resulta necesario subrayar las semejanzas entre el infinito matemático propuesto por Isidore Ducasse y el mito de Proteo. Dicha figura mitológica de la antigua Grecia congrega algunos de los elementos centrales en Les Chants: la matemática, la metamorfosis y particularmente la forma del agua.

En la mitología clásica, Proteo es una deidad marina de cuya figura ha escrito el propio Homero en la Odisea ${ }^{14}$. Para algunos, hijo del propio Poseidón, Proteo tiene la capacidad de cambiar constantemente y de allí proviene el adjetivo de «proteico». Pero hay algo en esta figura que resulta más pertinente para la descripción de la presente obra: «además de ser un dios de las aguas, y de la metamorfosis, Proteo es dios del número y del logos» (Zellini, 2018: 21).

Etimológicamente, el nombre de Proteo significa «primero» o «primogénito». La tensión que emerge entre la naturaleza cambiante de la deidad y su relación con el número revela la crisis que existe desde la Antigüedad en las matemáticas infinitesimales. Mientras que la metamorfosis apunta al continuo infinito, lo 1 equivale a lo discreto. Proteo cifra el conflicto entre el cambio perpetuo y la cuenta matemática como detención de lo ilimitado. En definitiva, la veracidad de la matemática está sujeta a la detención del continuo y la aprehensión de lo 1:

En el mito de Proteo están precisamente los polos de una complementariedad fundamental en el pensamiento de todos los tiempos: lo continuo y lo discreto. Por un lado, el mar y el continuo; por otro la operación de contar en lo discreto, de cinco en cinco, un logos abstracto y apolíneo que interviene cuando se miden cantidades o magnitudes mediante los números. Fue Tales quien situó en el elemento acuoso, continuo, el principio y el origen de todas las cosas y, al mismo tiempo, quien resolvió los primeros problemas de la geometría (Zellini, 2018: 30).

\footnotetext{
${ }^{13}$ Sobre la crisis del continuo ver: «Pero saber algo sobre los logros de Cantor no es lo mismo que valorarlos, lo cual constituye nuestro objetivo e implica ver las matemáticas transfinitas como una especie de árbol, con sus raíces en las paradojas de la Antigua Grecia acerca de la continuidad y la inconmensurabilidad, y sus ramas enredadas en la crisis moderna sobre los fundamentos de las matemáticas: Brouwer y Hilbert y Russell y Frege y Zermelo y Gödel y Cohen y sus colegas. Los nombres ahora mismo son menos importantes que el árbol, siendo este una especie de esquema general que conviene recordar» (Foster Wallace, 2013: 17).

${ }^{14}$ Ver Odisea, IV, 380-385: «Pues yo voy, extranjero, a explicártelo todo fielmente: / suele andar por aquí cierto anciano del mar, infalible, / el egipcio Proteo, inmortal que conoce los fondos / del océano sin fin; Posidón por vasallo lo tiene» (Homero, 1993: 153).
} 
En sentido similar al mito, la naturaleza en Lautréamont presenta un conflicto entre lo continuo y lo discreto. Y si bien el océano presenta las características más claras sobre dicha crisis, será la metamorfosis de las criaturas que pueblan el universo de Les Chants - principalmente a partir del canto cuartolo que fija este aspecto de la matemática.

Las transformaciones, a su vez, no solo afectan a Dios, al hombre y al propio narrador, sino que expresan la tónica de su poesía: «La métamorphose ne parut jamais à mes yeux que comme le haut et magnanime retentissement d'un bonheur parfait, que j'attendais depuis longtemps» (Ducasse, 1988: 350). Por otro lado, el cambio en la estructura biológica de las criaturas parece hacerse eco de las tesis evolucionistas de Darwin, que por entonces analizaba la transformación de las especies (Alonso, 2006: 157).

Pero más allá de este aspecto, resulta necesario subrayar el elemento fundamental que une tanto el mito de Proteo con la crisis del continuo expresada por Lautréamont: el agua. Como bien recuerda Zellini, el agua también fue un arché fundamental para los presocráticos, particularmente en el caso de Tales de Mileto. En sentido similar, muchas de las criaturas que mutan en el universo del franco-uruguayo provienen, al igual que el Proteo de Homero, de las profundidades marinas.

En effet, cet amphibie (puisque amphibie il y a, sans qu'on puisse affirmer le contraire) n'était visible que pour moi seul, abstraction faite des poissons et des cétacés; car, je m'aperçus que quelques paysans, qui s'étaient arrêtés à contempler mon visage, troublé par ce phénomène surnaturel, et qui cherchaient inutilement à s'expliquer pourquoi mes yeux étaient constamment fixés, avec une persévérance qui paraissait invincible, et qui ne l'était pas en réalité, sur un endroit de la mer où ils ne distinguaient, eux, qu'une quantité appréciable et limitée de bancs de poissons de toutes les espèces (Ducasse, 1988: 360).

Le Clézio (1986: 29) ya había señalado la presencia del anfibio en esta poética y subrayaba que «cet être est partagé entre la région de l'air et le monde sous-marin». Esta naturaleza doble y ambivalente responde al adjetivo de proteico que no solo califica las criaturas anfibias de Les Chants, sino que también determina su ars poetica: «Jusqu'à nos temps, la poésie fit une route fausse; s'élevant jusqu'au ciel ou rampant jusqu'à terre» (Ducasse, 1988: 318). Ducasse propone una síntesis en transformación donde se enlace el mundo abstracto de las ideas y la realidad terrenal de las palabras.

En definitiva, lo proteico en Lautréamont responde a la metamorfosis de las criaturas, pero también a la crisis del continuo. El mito de Proteo, encarnado por el anfibio, inscribe los números infinitesimales y determina la mirada del poeta que se desliza como un péndulo entre el mundo del aire (lo divisible y discreto) y la forma del agua (lo continuo). 


\section{Conclusiones}

Domesticar el infinito es una tarea transversal a los saberes que orbitan en Les Chants. Matemática, filosofía y poesía han fraguado su significado a partir de dos coordenadas fundamentales: espacio y tiempo. Hay que señalar a Anaximandro como el primero en situar al infinito en un espacio y tiempo anteriores a la creación. El arché indicado por el presocrático apunta al infinito como apeiron: informe, caótico e inabarcable.

Estas características negativas fueron suficientes para detener el estudio matemático del infinito de la mano de Platón y Aristóteles. El esplendor de Grecia oculta de esta manera la noción de infinito matemático bajo la lápida de la potencia. Durante el transcurso del período clásico y medieval, el infinito no era una entidad del espacio o de los números naturales, sino fundamentalmente una propiedad teológica.

Habría que esperar a la modernidad para volver a la noción de los espacios infinitos como propuso radicalmente Galileo. Pero cabe aclarar que el infinito se refiere esencialmente a dos dimensiones: una relativa a lo pequeño y la otra relativa a lo grande. Desde la perspectiva de la matemática, el infinito de lo pequeño se presenta bajo la forma de números fraccionarios, mientras que lo grande lo hace en la extensión ilimitada de los números naturales.

El desarrollo del cálculo concebido por Leibniz le permitió a la matemática abarcar los distintos campos del saber que buscan desentrañar la naturaleza. Dicha aprehensión colisiona directamente con la literatura $\mathrm{y}$ principalmente con el pensamiento poético. Durante los siglos XVII y XVIII el cientificismo comienza a agrietar la paz entre las dos culturas. Pero será a lo largo del siglo XIX cuando se escenifique un combate entre ambas fuerzas.

Sin embargo, poesía y matemática se embarcan en un modelo alternativo. El matrimonio entre ambos lenguajes, como podemos ver en Novalis o en el propio Lautréamont, es posible gracias a la búsqueda del infinito como signo de lo absoluto. En ambos casos se despliega un pensamiento platónico que sitúa a la poesía y a la matemática como formas que descienden de la Idea, en clara alusión a la tradición apolínea del número y el logos. Estas formas, a su vez, no pertenecen al universo de la materia, sino que lo trascienden para enlazar el pensamiento con un tiempo anterior a toda forma: to apeiron.

La literatura de Isidore Ducasse no es ajena al conocimiento científico de su tiempo, sino que instrumentaliza a su deseo conceptos provenientes de la óptica, la biología y particularmente la matemática. El franco-uruguayo se sitúa claramente entre aquellos que hacen dialogar matemática y poesía. La dirección del poeta es hacia el concepto de infinito desde ambas perspectivas. Como hemos expresado, y en la estela del romanticismo, Lautréamont identifica en el infinito aquello que Lacou-Labarthe y Nancy han llamado «absoluto literario». Para ello, el poeta materializa en el océano algunos de sus conceptos fundamentales.

La forma del agua ya sea por su extensión ilimitada como por su indivisibilidad, presenta algunas características que desde la Antigüedad se le han 
conferido al infinito. Inaprensible para la mirada y la razón, el paisaje oceánico adquiere la estética de lo sublime. Puesto que, como ha sugerido Kant, lo sublime matemático se gesta a partir de una magnitud ilimitada. Dicho paisaje provoca una búsqueda irrefrenable de domesticación y es desde allí desde donde zarpa el pensamiento del poeta.

De esta manera, el océano como espacio geométrico e infinito demuestra la tensión que el propio poeta evidencia en el seno de las matemáticas. Incluso más, el desafío central de su mirada sobre el mar es identificar en el continuo algún elemento de lo discreto. En definitiva, los sistemas de medición inventados por la ciencia no son suficientes para asegurar el conocimiento sobre las propiedades del suelo marino.

Bajo el signo de Proteo se puede identificar en Ducasse algunos elementos esenciales: la forma del agua, la metamorfosis, la matemática y fundamentalmente la crisis del continuo. En todos estos casos la propuesta del franco-uruguayo guarda cierta semejanza con el desarrollo de los números transfinitos a partir de Cantor en el siglo XIX. Como resultado, Lautréamont anticipa dos movimientos insondables hasta la actualidad en la filosofía de las matemáticas. El primero de ellos hace referencia a la crisis del continuo y el segundo al desplazamiento de los espacios ideales por las geometrías no-euclidianas.

A partir de la metáfora del agua y la constante transformación de los cuerpos que residen en su literatura, Lautréamont conduce la matemática hacia una crisis profunda de sus enunciados. Y si bien, bajo la intuición platónica, la matemática pertenece a un estado superior a la materia (incluso superior al propio demiurgo), Ducasse señala una transformación en sus principios éticos, donde la seguridad epistemológica de antaño se resquebraja en virtud de un nuevo modelo. Por tanto, si bien le confiere un valor metafísico, teológico y ontológico a la matemática, reconoce a su vez un cambio inminente en sus raíces profundas como resultado de una prolongada domesticación del infinito.

\section{REFERENCIAS BIBLIOGRÁFICAS}

Alonso, Ana (2006): «Metamorfosis ducassianas: un universo inestable». Barcarola: revista de creación literaria, 68-69, 155-166.

ARISTÓTELES (1995): Física. Introducción, traducción y notas de Guillermo R. de Echandía. Madrid, Gredos.

BACHELARD, Gaston (1939): Lautréamont. París, José Corti.

BÉGUIN, Albert (1967): L'âme romantique et le rêve. Essai sur le romantisme allemand et la poesie française. París, José Corti.

DUCASSE, Isidore (1988): Obra completa. Edición bilingüe. Traducción de Manuel Álvarez Ortega. Madrid, Akal.

FERNÁNDEZ URTASUN, Rosa (1999): «La poética de Lautréamont y la escritura vanguardista». Thélème. Revista complutense de estudios franceses, 14, 57-68. 
FOSTER WALlace, David (2013): Todo y más: breve historia del infinito. Barcelona, RBA Libros.

GONZÁLEZ FERNÁNDEZ, Francisco (2012): Esperando a Gödel. Literatura y matemáticas. Madrid, Nivola.

HERNÁNDEZ LEÓN, Juan Miguel (2016): Ser-Paisaje. Madrid, Abada.

HERSCH, Jeanne (2010): El gran asombro. La curiosidad como estímulo en la historia de la filosofía. Barcelona, Acantilado.

Homero (1993): Odisea. Traducción de José Manuel Pabón. Madrid, Gredos.

HUXLEY, Aldous (1964): Literatura y ciencia. Buenos Aires, Edhasa.

JAY GOULD, Stephen (2004): Érase una vez el zorro y el erizo. Las humanidades y las ciencias en el tercer milenio. Barcelona, Crítica.

JOFRE, Óscar ([1999] 2013): «Infinitos mundos y un solo Borges», in Sara Slapak, Borges y la ciencia, Buenos Aires, Eudeba, 145-152.

LACOUE-LABARTHE, Philippe \& Jean Luc NANCY (1978): L'absolu littéraire. Théorie de la littérature du romantisme allemand. París, Seuil.

LE ClÉZIO, Jean-Marie Gustave (1986): «Maldoror et les métamorphoses». Nouvelle Revue Française, 396, 23-44.

LYOTARD, Jean-François (2005): Le postmoderne expliqué aux enfants. París, Galilée.

MARTínEZ, Guillermo (2007): Borges y la matemática. Barcelona, Destino.

MARTíneZ MARZOA, Felipe (1995): Historia de la filosofía antigua. Madrid, Akal.

MeILlassouX, Quentin (2006): Après la finitude. Essai sur la necessité de la contingence. París, Seuil.

Novalis (1944): Diario íntimo. Himnos a la noche. Canciones espirituales. Cantos. Valencia, Editorial Horizontes.

ORTIZ, José Ramón (1994): «El concepto de infinito». Boletín de la Asociación Matemática Venezolana, I (2), 59-81.

PARCERISAS, Pilar (2006): «Lautréamont y el magnetismo de los tiempos modernos». Barcarola: revista de creación literaria, 68-69, 151-154.

PIERSSENS, Michel (1990): Savoirs à l'ouvre. Essais d'épistemocritique. Lille, Presses Universitaires de Lille.

PUIG PeÑalosA, Xavier (2009): «El concepto de ápeiron en Anaximandro: una estética del origen». Ontology Studies, 9, 131-138.

SOLLERS, Philippe (1968): L'écriture et l'expérience des limites. París, Seuil.

STEINER, George (2005): Gramáticas de la creación. Traducción de Andoni Alonso y Carmen Galán Rodríguez. Madrid, Siruela.

TASIC, Vladimir (2001): Una lectura matemática del pensamiento postmoderno. Buenos Aires, Ediciones Colihue.

ZELlini, Paolo (2007): La rebelión del número. Madrid, Sexto Piso.

ZELLINI, Paolo (2018): Número y «logos». Barcelona, Acantilado. 